\title{
Factors associated with institutional delivery among the rural women in Bangladesh
}

\author{
AC Das ${ }^{1,2}$, MK Biswas ${ }^{1,2}$
}

\begin{abstract}
Maternal mortality and morbidity rates in Bangladesh along with poor health care access are still high. The aim of this study was to identify associated factors with institutional delivery among rural women in Bangladesh. The cross sectional study conducted among the rural women aged 15-49 years old in seven sub-districts of Bhola district, Bangladesh. The study sample size was 250 rural women who were purposively selected. Hazards Model Analysis, namely univariate (Model 1) and multivariate (Model 2) binary logistic regression analyses, was performed in the final analysis. Employing the hazards analysis, the study had identified that the maternal characteristics such as mother's education, age, and media exposure were more important covariates associated in explaining institutional delivery (Model 1). Education of mother, exposure of media, and family income were strongly and positively associated with the risk of termination of institutional delivery in the both Model 1 and Model 2. Mothers with higher education have a positive significant effect on the termination of institutional delivery, when compared with women of education below secondary. The findings of the present study are likely to the government and policy makers to take appropriate measures to decrease delivery complexities and mortalities by increasing institutional delivery facility where the facility is lacking.
\end{abstract}

Key words: Maternal mortality, institutional delivery, cross-sectional study, Bangladesh.

\section{Introduction}

Reduction of maternal mortality is a global priority particularly in developing countries including Bangladesh where maternal mortality ratio is one of the highest in the world. The key to reducing maternal mortality ratio and improving maternal health is increasing attendance by skilled health personnel throughout pregnancy and delivery. ${ }^{1}$ Maternal mortality rate, the death of women during pregnancy, childbirth, or in the 42 days after delivery, is on the decline in Bangladesh, but remains very high estimated 194 maternal deaths per 100000 live births. ${ }^{2}$ Women and their families face socioeconomic and cultural barriers to seeking professional delivery care, such as high costs, long distances to health facilities, lack of knowledge about danger signs during pregnancy, and a tradition of using untrained local practitioners during delivery. 3 However, appropriate delivery care is crucial for both maternal and neonatal health and it is considered that increasing skilled attendance at birth is a central goal of the safe motherhood and child survival movements. ${ }^{4}$ In addition to

1. Department of Population Sciences, University of Dhaka, Dhaka-1000, Bangladesh. email: akkurdas@gmail.com

2. Bangladesh Country Coordinating Mechanism, Ministry of Health and Family Welfare, Bangladesh Secretariat, Dhaka-1000, Bangladesh 
In addition to professional attention, it is important that mothers deliver their babies in an appropriate setting, where lifesaving equipment and hygienic conditions can also help in reducing the risk of complications that may cause death or illness to mother and child. ${ }^{5}$

Babalola and Fatusi (2009) found by their study that utilization of maternal health services is associated with improved maternal and neonatal health outcomes where there are many factors influencing maternal health services utilization to operate at various levels- individual, household, community and state while education, socioeconomic level, and urban residence are consistently strong predictors of all the maternal health services considered in the study; other determinants of service utilization generally vary in magnitude and level of significance by the type of maternal services- antenatal care, skilled attendant at birth, and postnatal care. ${ }^{6}$ The results from another study provide a new way to conceptualize a husband's involvement in his wife's decision to seek professional delivery care in rural Bangladesh. ${ }^{7}$ Long distance can be an obstacle to reaching a health facility as well as a disincentive to even try to seek care and it is noted that rural populations are particularly disadvantaged as they often lack reliable means of transportation; a sizable proportion of maternal deaths in developing countries occur on the way to hospital and other women are almost beyond help by the time they arrive. 8 It is also revealed by the study that mothers who visited antenatal care during last pregnancy were about four times more likely to deliver in health facilities than mothers who did not visit antenatal care. ${ }^{1}$

Wong et al (1987) showed that family size is one of the important predisposing factors for utilization of health care where women from large families underutilize various healthcare services because of too many demands on the same time. Larger families also cause resource constraints, which have a negative effect on health care utilization. ${ }^{9}$ Thus, antenatal care may be particularly advantageous in resource-poor developing countries, where health seeking behavior is inadequate, access to health services is otherwise limited, and most mothers are poor, illiterate or rural dwellers; but with the strong positive association that has been shown to exist between level of care obtained during pregnancy and the use of safe delivery care, and antenatal care also stands to contribute indirectly to maternal mortality reduction. ${ }^{10}$

To increase institutional delivery, planned interventions should be taken by targeting women with two or more living children, women with low levels of formal education, and women from the poorest households. The substantial effect of belonging to a wealthier household and the effect of greater personal autonomy on institutional delivery suggest that more attention needs to be paid to the role of the husband in supporting the wife's decision to deliver in a health facility. ${ }^{11}$ Maternal health needs to become a political priority. ${ }^{12}$ Strategies with focus on increasing antenatal care uptake and increasing maternal and their partners' educational level help to increase health facility delivery service utilization. ${ }^{13}$ Despite, few studies had taken place but there is much lacking of information that can point the associated factors most relevant in institutional delivery. Therefore, the aim of this study was to identify associated factors with institutional delivery among rural women in Bangladesh. Moreover, this information is necessary for service providers and district health management teams for improving the quality of institutional delivery services provided in both the first-lined and referral health institutions in Bangladesh.

\section{Materials and Method}

Study site, design and participants' recruitment

The study was a cross sectional study, which was conducted among the rural women aged 15-49 years old in seven upazilas (subdistricts) of Bhola district, Bangladesh. The study sample size was 250 rural women who were purposively selected. There are 60 unions in seven sub-districts and from each sub-district 4 unions were selected randomly. 
Total unions were taken 28 among 60 unions for the data collection. Twenty nine women from Bhola Sadar Upazila, 22 women from Burhanuddin Upazila, 36 women from Charfasson Upazila, 21 women from Daulatkhan Upazila, 29 women from Lalmohan Upazila, 74 women from Manpura Upazila, 39 women were interviewed from Tazumuddin Upazila. To be eligible for the study, women were required to: a) live in the study locations during the survey, b) age 15-49 years old ever married women, and c) women who had at least one delivery experience and also gave birth in the last 12 months. Only one woman from each household $(\mathrm{HH})$ was interviewed if more than one eligible woman were found. If an eligible woman was not found in a $\mathrm{HH}$, an adjacent $\mathrm{HH}$ was approached. Although selected conveniently, the study attempted to get a sample from different religions, and socio-economic conditions. However, difficulties in obtaining a representative sample based on the above mentioned criteria included the remote locations of these seven study sites, transportation problems and lack of educated female interviewers.

\section{Data collection}

A pre-tested survey questionnaire was developed and used for data collection. The questionnaire was developed in English and translated into Bangla and verified by a process of back-translation. Eight female interviewers having 10 to 16 years of schooling from the rural community were recruited to conduct the face-to-face interview survey. Of eight, five interviewers were working as health workers in non-government organizations. Specifically, three took formal training as a midwife from a private medical college hospital, two interviewers were students, and the others were housewives. The final data collection took place from October to December 2014. Informed consent was taken verbally from participants before starting face-to-face interviewing because most of them could not read or write.

\section{Statistical analysis}

The Statistical Package for Social Sciences (SPSS) software (version 20.0; SPSS Inc., Chicago, IL, USA) was employed for data analyses. Bivariate and multivariate analyses were performed based on cross tabulations using chi-square tests, and binary logistic regression analysis in multivariate analyze. Frequencies and proportions were calculated to describe the sample, according to the outcome of interest and other sociodemographic characteristics. In multivariate analysis, binary logistic model was used to explore the factors influencing institutional delivery. Here, institutional delivery was coded as 1 and other type of situation (noninstitutional delivery) was coded as 0 . The results of multivariate logistic regression model were reported as odds ratio (OR) and data underwent consistency, logical and range checks prior to analysis in SPSS. Descriptive statistics were performed on all questions.

\section{Model specification for \\ Hazards Model Analysis}

A multivariate analysis of institutional delivery is made by proportional hazards regression using eight independent variables as predictors. For selection of these variables, a set of 12 variables were initially selected from available information in the data for univariate hazards analysis and the variables which came out significant at the 10 percent levels were finally selected for the multivariate hazards analysis. The twelve variables were used in univariate (Model 1) hazards analysis are respondent's age, respondent's education, husband's age, husband's education, respondent's occupation, husband's occupation, household headship, family income, number of children, media exposure, religion and visit of health workers.

A total eight variables came out significant at the 10 percent level in the analysis. The variable age of the husbands, religion, visit of health workers, and mother's current occupational status had insignificant effects on institutional delivery so that they were not included in the multivariate (Model 2) analysis. In the present study, two models were fitted in multivariate hazards analysis. Model 2 was constructed by including all eight variables. Relation to Model 2, Model 1 deletes the variable husband's education and household headship. The variable mother's current 
Table 1. The definitions and coding of independent variables used in the analysis

\begin{tabular}{ll}
\hline Independent variables & Definition \\
\hline Respondent's age & Under 18 years $=0$ \\
& 18 years or above $=1$ \\
Respondent's education & $\leq$ Primary $=0$ \\
& Secondary or above $=1$ \\
Husband's education & $\leq$ Primary $=0$ \\
& Secondary or above $=1$ \\
Respondent's occupational status & Unemployed $=0$ \\
& Employed $=1$ \\
Household headship & Female $=0$ \\
& Male $=1$ \\
Family income & Below 2000 taka $=0$ \\
& 2000 taka or above $=1$ \\
Number of children & Women with the number of children 1-2 = 0 \\
& $\geq 3=1$ \\
& Number of children $1-2=$ size of an ideal family \\
Media exposure & No $=0$ \\
& Yes $=1$ \\
\hline
\end{tabular}

occupational status measured only whether a women was working for money during the study. The definitions of independent variables used and recoded for the final analysis are shown in Table 1.

\section{Results}

Background characteristics of the study participants

Table 2 shows the background characteristics of 250 respondents in this study. Of 250 surveyed ever married women, $4.4 \%$ were less than 18 years, $82.4 \%$ aged $18-33$ years while $10 \%$ aged $34-49$ years. The findings of this study showed that most of the respondents $(91.2 \%)$ had the exposure of media and only $8.8 \%$ had no media exposure, $55.2 \%$ women were employed and $44.8 \%$ unemployed. The level of education of the respondents revealed that $50.8 \%$ received primary education and $41.2 \%$ secondary education. Only $8 \%$ had no education. But the level of education of the respondents' husband revealed that $45.2 \%$ received primary education and $40.4 \%$ secondary education while $14.4 \%$ had no education. The findings of this study also revealed that $79.2 \%$ respondents' family was in the income level of $1001-2000$ taka, and $12.8 \%$ in the income level of 2001-3000 taka while $8 \%$ in the income level of 1-1000 taka. Most of the respondents $(55.2 \%)$ had 2 children, $22 \% 3$ and $13.6 \% 4$ children. Only $9.2 \%$ had 1 child. It was also found that majority $(91.2 \%)$ had the household headship of male but female household headship only $8.8 \%$. However, Fig. 1 shows that majority (76\%) women had no institutional delivery experience while $24 \%$ had institutional delivery experience.

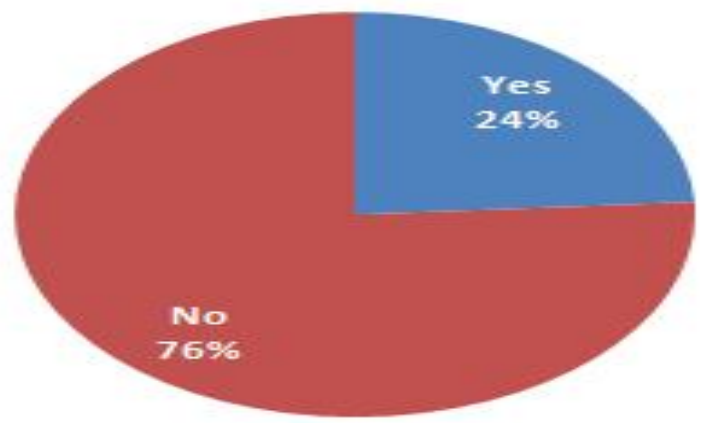

Fig. 1. Number of institutional delivery, $n=250$. 
Table 2. Percentage distribution of evermarried women less than 50 years old by selected characteristics, $n=250$

\begin{tabular}{|c|c|c|}
\hline Characteristics & $\mathbf{n}$ & $\%$ \\
\hline Respondent'sage & 11 & 4.4 \\
\hline$<18$ & 206 & 82.4 \\
\hline $18-33$ & 25 & 10.0 \\
\hline \multicolumn{3}{|l|}{$34-49$} \\
\hline \multicolumn{3}{|l|}{ Respondent's education } \\
\hline No education & 20 & 8.0 \\
\hline Primary & 127 & 50.8 \\
\hline Secondary orhigher & 103 & 41.2 \\
\hline \multicolumn{3}{|l|}{ Husband's education } \\
\hline No education & 36 & 14.4 \\
\hline Primary & 113 & 45.2 \\
\hline Secondary or Higher & 101 & 40.4 \\
\hline \multicolumn{3}{|l|}{ Respondent's œcupation } \\
\hline Unemployed & 112 & 44.8 \\
\hline Employed & 138 & 55.2 \\
\hline \multicolumn{3}{|l|}{ Household headship } \\
\hline Female & 22 & 8.8 \\
\hline Male & 228 & 91.2 \\
\hline \multicolumn{3}{|l|}{ Family income } \\
\hline $1-1000$ & 20 & 8.0 \\
\hline $1001-2000$ & 198 & 79.2 \\
\hline $2001-3000$ & 32 & 12.8 \\
\hline \multicolumn{3}{|l|}{ Number of children } \\
\hline 1 & 23 & 9.2 \\
\hline 2 & 138 & 55.2 \\
\hline 3 & 55 & 22.0 \\
\hline 4 & 34 & 13.6 \\
\hline \multicolumn{3}{|l|}{ Media exposure } \\
\hline No & 22 & 8.8 \\
\hline Yes & 228 & 91.2 \\
\hline
\end{tabular}

Table 3 shows the results of the present study by hazards analysis show that maternal characteristics such as mother's education, mother's age, and media exposure are more important covariates in explaining institutional delivery those are strongly and positively associated (at 5 percent levels) with the risk of termination of institutional delivery in both the models. Spousal characteristics such as husband's education have come out negatively associated and significant at the 10 percent level in the final model (Model 2); but family income has positively and strongly associated in the both the models. Mothers with higher education have a positive significant effect on the termination of institutional delivery, when compared with women of education below secondary. This means that mother's education has positive significant effect on institutional delivery. Number of children is found to have a positive and insignificant effect on the risk termination of institutional delivery in Model 1but strongly associated in final model (at 5 percent levels). This indicates that increase in number of children is associated with a decrease in the probability of weaning, i.e., women with higher number of children are associated with extended institutional delivery. Mother's age has positive significant effect on the institutional delivery. However, only women 
Table 3. Estimated regression coefficients (b) and relative risks of termination of institutional delivery for proportional hazards analysis on some selected characteristics

\begin{tabular}{|c|c|c|c|c|}
\hline \multirow[t]{2}{*}{ Characteristics } & \multicolumn{2}{|c|}{ Model 1} & \multicolumn{2}{|c|}{ Model 2} \\
\hline & (b) & $\operatorname{Exp}(b)$ & (b) & $\operatorname{Exp}(b)$ \\
\hline Respondent's age (reference $=<18$ years) & .457 & $1.596^{* \star}$ & .503 & $1.654^{\star \star}$ \\
\hline $\begin{array}{l}\text { Respondent's education (reference = no } \\
\text { education) }\end{array}$ & .595 & $2.551^{* *}$ & .560 & $2.571^{\star *}$ \\
\hline $\begin{array}{l}\text { Husband's education (reference }=\text { no } \\
\text { education) }\end{array}$ & - & - & -.639 & $.528^{\star}$ \\
\hline $\begin{array}{l}\text { Respondent's occupation (reference= } \\
\text { unemployed) }\end{array}$ & .313 & $1.269 * *$ & .568 & $1.208^{* * *}$ \\
\hline Household headship (reference $=$ female) & - & - & -.717 & $.488^{* *}$ \\
\hline Family income (reference $=<2000$ taka) & 1.388 & $4.005^{\star \star}$ & 1.558 & $4.751^{\star \star}$ \\
\hline Number of children (ref erence $=1-2$ ) & .320 & $2.273^{*}$ & .376 & $2.253^{\star *}$ \\
\hline Media exposure (reference $=$ no) & .940 & $2.561^{* \star}$ & .877 & $2.404^{\star \star}$ \\
\hline
\end{tabular}

$$
{ }^{\star \star \star}: p<0.01,{ }^{\star \star}: p<0.05,{ }^{\star}: p<0.10
$$

However, only women more than the age of 18 have a significantly lower hazard of weaning than those aged 18. Media exposure is found to have positive and significant (at 5 percent levels) effect on the risk of termination of institutional delivery in the both models. However, in the final model (Model 2) when husband's education and household headship are included; number of children comes strongly significant.

\section{Discussion}

Maternal health care services are associated with improved maternal and neonatal health outcomes where many factors influences maternal health services to operate at various levels- individual, household, community and state while education, socioeconomic level, and urban residence are consistently strong predictors of all the maternal health services; but other determinants of service utilization generally vary in magnitude and level of significance by the type of maternal services- antenatal care, skilled attendant at birth, and postnatal care. Evidence suggests that having skilled attendants at delivery is one of the key interventions for reducing maternal mortality. ${ }^{14}$ On the other hand, key factors associated with the uptake of skilled delivery care included: age, ethnicity, occupation, and education of women, occupation and education of their husbands, and number of pregnancies and children, use of antenatal care, and the experience of problems during pregnancy.

The main barriers to accessing skilled delivery were distance to hospital and costs associated with a delivery at hospital. Health problems during delivery, such as long labour and retained placenta, were not common but they were included in the main reasons for seeking intra-partum care late. ${ }^{15}$ Majelantle and Letamo (1999) found that some women preferred delivery at home and to be assisted during the delivery by traditional birth attendants because the traditional birth attendants were considered to be more compassionate and caring than modern healthcare providers. ${ }^{16}$ Education showed the strongest relationship with non use of institutional delivery. That is, the women with no education were less likely to use maternal services. ${ }^{17}$ Many associated factors relating to the use of skilled delivery care that were identified included age, education and occupation of women, and education and occupation of husbands. Therefore, the availability of skilled delivery care services at the community, initiation of a primary health centre with skilled staff for delivery, and increasing awareness among women to seek skilled delivery care are the best solution. ${ }^{15}$ 
The factors that were found to be associated with institutional delivery were residential place, educational level of mothers and husbands, antenatal care follow up and being birth prepared and ready for its complication. Urban mothers were 3.6 times more likely to deliver at health institutions than rural mothers. ${ }^{13}$ Hence, an important component in the effort to reduce the health risks of mothers and children is to increase the proportion of babies delivered in a safe and clean environment and under the supervision of health professionals. ${ }^{18-20}$

\section{Conclusions}

This study revealed that the proportion of women who gave birth at health facilities was low. Rural women's age, secondary and post-secondary levels of education of mothers and family income were significantly associated with institutional delivery service utilization. The education of mother was strongly and positively associated with the risk of termination of institutional delivery in both the models used in this study. Mothers with higher education had a positive significant effect on the termination of institutional delivery, when compared with women of education below secondary. Media exposure was also found to have significant effect on the risk of termination of institutional delivery in both models. However, in the multivariate model when husband's education and household headship are included; number of children comes strongly significant. Family income was positively and strongly significant in the both models. Increasing the awareness of mothers and their partners including other family members about the benefits of institutional delivery services were recommended to develop the overall health status of Bangladesh.

\section{Acknowledgement}

The authors would like to thank the participants who participated in this study willingly and gave the valuable information. We also thank all those people who directly and indirectly helped us doing this research.

\section{Conflict of interest}

The authors declared that there is no conflict of interest.

\section{References}

1. Teferra AS, Alemu FM, Woldeyohannes SM. Institutional delivery service utilization and associated factors among mothers who gave birth in the last 12 months in Sekela District, north west of Ethiopia: a community-based cross sectional study. BMC pregnancy childbirth 2012;12:74.

2. Bangladesh Maternal Morality and Health Care Survey (BMMS). Summary of key findings and implications; 2010. http://www.dghs.gov.bd/dmdocuments/ BMMS_2010.pdf (Accessed on November 25, 2015).

3. Adeleye OA, Chiwuzie J. "He does his own and walks away" perceptions about male attitudes and practices regarding safe motherhood in Ekiadolor, Southern Nigeria. Afr J Reprod Health 2007;11:76-89.

4. Kesterton AJ, Cleland J, Sloggett A, Ronsmans C. Institutional delivery in rural India: the relative importance of accessibility and economic status. BMC pregnancy childbirth 2010; 10:30.

5. Campbell OM, Graham WJ, on behalf of The Lancet Maternal Survival Series Steering Group: Strategies for reducing maternal mortality: getting on with what works. Lancet 2006;368(9543):1284-99.

6. Babalola S, Fatusi A. Determinants of use of maternal health services in Nigeria-looking beyond individual and household factors. BMC pregnancy childbirth 2009;9:43.

7. Story WT, Burgard SA, Lori JR, Taleb F, Ali NA, Hoque DE. Husbands' involvement in delivery care utilization in rural Bangladesh: a qualitative study. BMC pregnancy childbirth 2012;12:28.

8. Ronsmans C, Graham WJ, on behalf of the Lancet Maternal Survival Series Steering Group. Maternal mortality: who, when, where and why. Lancet 2006;368:1189-200.

9. Wong EL, Popkin BM, Gullkey DK, Akin JS. Accessibility, quality of care and prenatal care use in the Philippines. Soci Sci Med 1987;24:927-44.

10. Bloom SS, Wypij D, Gupta M. Dimensions of women's autonomy and the 
influence on maternal health care utilization in a north Indian city. Demography 2001;38:67-78.

11. Agha S, Carton TW. Determinants of institutional delivery in rural Jhang, Pakistan. Int J Equity Health 2011;10:31.

12. Mavalankar D, Vora K, Prakasamma M. Achieving Millennium Development Goal 5: is India serious? Bull World Health Organ 2008;86(4):243-243A.

13. Odo D, Shifti D. Institutional delivery service utilization and associated factors among child bearing age women in Goba Woreda, Ethiopia. J Gynecol Obstet 2014; 2(4):63-70.

14. WHO/FIGO/International Confederation of Midwives. Definition of the midwife. The Hague: International Confederation of Midwives, 1992.

15. Dhakal S, Van Teijlingen E, Raja EA, Dhakal KB. Skilled care at birth among rural women in Nepal: practice and challenges. J Health Popul Nutr 2011; 29(4):371-8.
16. Majelantle RG, Letamo G. The reproductive health problems of teenage child- bearing in Botswana/edited by HM Yousif. Gaborone: National Council on Population and Development, Ministry of Finance and Development Planning. Research Paper No. 1; 1999.

17. Letamo G, Rakgoasi SD. Factors associated with non-use of maternal health services in Botswana. J Health Popul Nutr 2003;21(1):40-7.

18. Kamal SMM. Preference for institutional delivery and caesarean sections in Bangladesh. J Health Popul Nutr 2013;31(1):96-109.

19. Central Statistical Agency and ORC Macro. Ethiopia Demographic and Health Survey 2005: Addis Ababa. Central Statistical Agency and ORC Macro; 2005.

20. Nanda G, Switlick K, Lule E. Accelerating progress towards achieving the MDG to improve maternal health: a collection of promising approaches. HNP, World Bank. 2005.

\section{Suggestion for citation of the above:}

Das AC, MK Biswas. Factors associated with institutional delivery among the rural women in Bangladesh. Mediscope 2016;3(2):18-25. 